\title{
Absorbance Unit per Minute
}

National Cancer Institute

\section{Source}

National Cancer Institute. Absorbance Unit per Minute. NCI Thesaurus. Code C73687.

A unit of a speed of optical density change expressed as a logarithm of absorbance of light transmitted through a partially absorbing substance per minute. 